\title{
Causal Perceptions in Turkish Parents of Children with Cancer
}

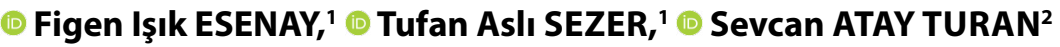 \\ 'Department of Pediatric Nursing, Faculty of Nursing, Ankara University, Ankara-Turkey \\ ${ }^{2}$ Department of Pediatric Nursing, Faculty of Nursing, Akdeniz University, Ankara-Turkey
}

\begin{abstract}
OBJECTIVE
To more fully explore how the parents of childhood cancer patients perceive the causes of their disease.

\section{METHODS}

This cross-sectional study included 229 parents of children with cancer who were admitted at one of the largest children's hematology and oncology clinics in Ankara, Turkey. The parents completed the causal representations subscale of the Illness Perception Questionnaire. Analyses of variance and other descriptive tests were performed.

\section{RESULTS}

The most common causal attributions were a function of the Risk Factors Subscale $(M=2.94)$ pertaining to diet and eating disorders. The answers to the open-ended questions indicated that the most significant issue in their children's disease was faith-based, the will of God, and the "evil eye" (43.9\%). The mean scores on the subscale did not vary by parental, marital, educational status, region of residence, or time of diagnosis; there was only a significant difference based on income level and age.
\end{abstract}

\section{CONCLUSION}

Parents responding in a self-report on the causal representations subscale suggested that most risk factors involved more fatalistic views, which were due to societal differences. This is important for clinicians, who plan and implement education and treatment, to better understand parents' perceptions regarding cancer. Our findings highlight the need for more attention to these cultural matters in cancer care.

Keywords: Childhood cancer; cancer perception; parents.

Copyright $\odot$ 2018, Turkish Society for Radiation Oncology

\section{Introduction}

The International Agency for Research on Cancer report indicates that about 300,000 children aged $<19$ years worldwide were diagnosed with cancer between 2001 and 2010. It is estimated that childhood cancer causes 80,000 deaths worldwide every year.[1] According to the records of the Turkish Pediatric Oncology
Group from 2002 to $2009,11,898$ children were affected with cancer in Turkey.[2] Childhood cancers used to have high mortality rates; however, today cancer has become a life-threatening chronic disease rather than a mortal disease thanks to advances in cancer treatment. [3] Despite this significant decrease in mortality, the perception of mortal disease lingers within the society. Cancer is a disease that arouses feelings of fear, uncer- 
tainty, guilt, helplessness, and death.[4,5,6,7] Therefore, the diagnosis of cancer in children negatively affects both the children and their parents emotionally, socially, mentally, and spiritually, apart from the physical effects of cancer. [3,8]

Although the causes of childhood cancer are not known with certainty, some structural and environmental risk factors that play a role in the development of cancer have been identified. These include congenital or genetic anomalies, immunodeficiency syndromes, virus infections, exposure to radiation or some chemicals [such as benzene or pesticides], and some medicines used during pregnancy.[9] Individuals may develop theories about the cause of cancer that may not be based on scientific knowledge. Such attempts to understand or make sense of the illness are described as causal attributions.[10] Causal attributions can be classified by locus [internal or external], controllability, and modifiability.[11]

Previous studies have shown that people's opinions on the causes of cancer are differs. For example, adult cancer patients have stated the causes of cancer to be mostly misfortune or bad luck.[12] Patients with lung cancer listed the causes of their disease to be smoking, bad luck, working hard, stress, genetic, or familial factors, nutritional habits, or work environment.[6] In a large study of American Cancer Society on cancer survivors, the 10 most common causes of cancer declared were lifestyle, biological, environmental, smoking, chance/luck, stress, existential, prior health condition, psychological.[11]

The level of knowledge regarding the causes of childhood cancer among parents remains uncertain. [5] The limited number of studies conducted on parents of children with cancer reported that the parents stated psychosocial problems [13], emotional stress and nutrition [14], and faith and their insufficiency in their maternal role.[15] In the studies conducted on parents of healthy children in Turkey, the participants stated that cancer is most frequently caused by smoking, foods (prepared food stuffs, food additives, barbecue, tea, etc.), alcohol, radiation, environmental pollution, stress, sorrow, genetic factors, sun, bacteria or viruses, or cell phones.[5] There is no study about causal perceptions in Turkish parents of children with cancer. As known, perceptions vary by cultural characteristics; hence, this study will contribute to the literature about these cultural differences.

Causal attributions may affect cancer survivors' quality of life, psychosocial adjustment, and distress levels $[11,16]$, and they may increase one's perception of control [17], which could affect overall adjustment to a cancer diagnosis. Nevertheless, parents understanding the causes of their children's disease could affect coping, reduction of negative beliefs, effective control of the treatment process, prevention of cancer, and adherence to postcancer treatment. $[14,18]$ Positive compliance of parents with the treatment contributes to the children's adherence to the disease and treatment process along with their development. $[8,13,14,19]$

Determining the parents' causal attributions for their children's cancer could be guide pediatric nurses to plan family-oriented interventions and ensure the compliance of children and their parents with treatment. This study aims to determine parents' causal attributions for their children's illness and differences according to sociodemographic factors.

\section{Materials and Methods}

\section{Sample and Setting}

This study had a cross-sectional design. The sample consisted of the parents of the patients hospitalized between February 2014 and January 2015 in the Pediatric Hematology and Oncology Unit of Ankara University Cebeci Children's Hospital $(n=229)$ who agreed to participate in the study with consecutive sampling. This hospital accepts patients from all over Turkey because it has one of the largest children's hematology and oncology clinics in the capital city of Turkey.

Inclusion criteria were being a parent of a cancer patient hospitalized in the Pediatric Hematology and Oncology Unit of Ankara University Cebeci Children's Hospital. Parents who have cognitive/neurological problems and who refuse to participate in the study were excluded from the study.

\section{Measures}

The data were collected using an Introductory Information Form and the Causal Representations subscale of the Illness Perception Questionnaire (IPQ). The scales were administered by the researchers to the parents who met the inclusion criteria and agreed to participate in the study. Questionnaires fulfilled with face-to-face interviews in the parent's resting area.

The Introductory Information Form. This was prepared by the researchers and consisted of eight questions on the age, gender, marital status, educational status, socioeconomic status, region of residence, children's diagnosis, and the time passed after the children had been diagnosed. 
Table 1 Sociodemographic information of the participants

\begin{tabular}{|c|c|c|}
\hline Socio-demographics & $\mathbf{n}$ & $\%$ \\
\hline \multicolumn{3}{|l|}{ Parental Status } \\
\hline Mother & 212 & 92.6 \\
\hline Father & 17 & 7.4 \\
\hline \multicolumn{3}{|l|}{ Parental age (years) } \\
\hline $19-24$ & 12 & 5.2 \\
\hline $25-30$ & 41 & 17.9 \\
\hline $31-35$ & 61 & 26.6 \\
\hline $36-40$ & 61 & 26.6 \\
\hline $41-45$ & 36 & 15.7 \\
\hline $46+$ & 18 & 7.9 \\
\hline \multicolumn{3}{|l|}{ Marital Status } \\
\hline Married & 221 & 96.5 \\
\hline Single/Divorced & 8 & 3.5 \\
\hline \multicolumn{3}{|l|}{ Income Level } \\
\hline Medium & 135 & 59.0 \\
\hline Low & 83 & 36.2 \\
\hline High & 11 & 4.8 \\
\hline \multicolumn{3}{|l|}{ Education Status } \\
\hline Illiterate & 11 & 4.8 \\
\hline Primary school & 95 & 41.5 \\
\hline Secondar school & 31 & 13.5 \\
\hline High school & 65 & 28.4 \\
\hline Graduate/Postgraduate & 27 & 11.9 \\
\hline \multicolumn{3}{|l|}{ Region of Residence } \\
\hline Ankara & 102 & 44.5 \\
\hline Outside of Ankara & 127 & 55.5 \\
\hline \multicolumn{3}{|l|}{ Time of diagnosis } \\
\hline $0-6 \mathrm{mth}$ & 66 & 28.82 \\
\hline $7-12 \mathrm{mth}$ & 75 & 32.75 \\
\hline $13-60 \mathrm{mth}$ & 78 & 34.06 \\
\hline Over 60 mth & 10 & 4.36 \\
\hline \multicolumn{3}{|l|}{ Diagnoses } \\
\hline Leukemia & 103 & 45.0 \\
\hline Lymphoma & 19 & 8.3 \\
\hline Central Nervous System tumours & 22 & 9.6 \\
\hline Neuroblastoma & 6 & 2.6 \\
\hline Retinablastoma & 8 & 3.5 \\
\hline Nephroblastoma & 1 & 0.4 \\
\hline Hepatoblastoma & 4 & 1.7 \\
\hline Bone Tumours & 48 & 21.0 \\
\hline Soft Tissue and Extraosseal Tumours & 8 & 3.5 \\
\hline Malignant Epithelial Carcinomas & 1 & 0.4 \\
\hline Others & 9 & 3.9 \\
\hline
\end{tabular}

The Causal Representation Subscale of the IPQ. This was used to determine the causes of cancer perceived by parents of children diagnosed with cancer. Questionnaire was developed by Weinman (1996) [10], revised by Moss-Morris et al. (2002) [21] and adapted in Turkish by Armay et al. in 2007.[4] The Causal Representa- tion Scale, a five-point (from 1 representing "strongly disagree" to 5 representing "strongly agree") Likert type, consists of four subdimensions and a total of 18 items. The subdimensions are Psychological Attributions, Risk Factors, Immunity, and Accidental, or Chance. The scale, developed to determine the causes of disease in adult patients, was re-organized for adaptation to childhood cancers. The item "My mental attitude" was excluded from the possible causes, and the item "aging" was changed to "growing." A pilot administration was performed with parents of 10 children with cancer using the final subscale with 17 items. In addition, the parents were asked to indicate the three most significant causes of their children's disease (they could either make choices from the table in the subscale or write what they thought to cause cancer) to allow qualitative assessment. The aim was to learn the parents' own thoughts beyond subscale limitations. Causal representations subscales were reported high internal reliability and Cronbach's alpha value ranging from 0.41 to 0.78 .[4] In the present study, the Cronbach's alpha coefficient of the Causal Representations subscale was found to range between 0.42 and 0.66 [Table 2].

\section{Data Analyses}

The sociodemographic data were analyzed using descriptive statistical analysis (frequency, mean, and percentage) methods. The multiple analysis of variance (MANOVA) test was used to analyze the total scores of the Causal Representation subscales according to independent variables (sociodemographics as age, parental status, marital status, education status, income level, region of residence, and time of diagnosis variables). Post hoc (Schefe) tests were used to find out, which variable is the source of the difference. All analyses were performed using the SPSS 21 package.

\section{Ethical Consideration}

The study was conducted according to the precepts of the Helsinki Declaration. The approval of the Ethics Committee of Ankara University Rectorate (Decision no: 1288 , Dated: 10.1.2014) and the permission of the Head of Ankara University Cebeci Children's Hospital were obtained to conduct the study. The aim of the study was explained to the parents and their informed consents were obtained.

\section{Results}

The study included 229 parents staying with their hospitalized children. A majority (92.6\%) of the primary 
caregivers of the children were their mothers. The average age was $35.8 \pm 7.00$ years for mothers, $38 \pm 9.88$ years for fathers, and $8.24 \pm 5.52$ years for children. Of the parents, $41.5 \%$ had graduated from primary school, and $55.5 \%$ came from outside Ankara. The time of disease diagnosis was mostly $1-5$ years (34\%).

The children in this study were mostly diagnosed with leukemia (45\%) and osseous tumors (21\%). This distribution was similar to the distribution of childhood cancers in Turkey.[20] Although the prevalence of childhood cancers differs by country, leukemia is the most frequently observed childhood cancer type around the world, with a rate of 35\%.[1] Table 1 shows the sociodemographic information of the parents and children. Table 2 shows the mean scores of the subdimensions. It was 2.94 for risk factors, 2.39 for immunity, 1.76 for accident or chance, and 1.69 for the Psychological Attributions subdimension.

The MANOVA test showed that the total scores of the Causal Representation subscale did not vary by parental status, marital status, education status, region of residence, and time of diagnosis ( $p>0.05)$. Mean score of the parents on the Psychological Attributions subdimension was found to show a statistically significant difference according to their income level $(\mathrm{F}=4.410$; $\mathrm{p}=0.013$ ). The parents with a low income level obtained higher scores on the Psychological Attributions subdimension than those with a medium income level.

The mean score of the parents on the Psychological Attributions and Risk Factors subdimensions were found to show a statistically significant difference according to their age. The older parents obtained higher scores on the Psychological Attributions ( $\mathrm{F}=2.558$; $\mathrm{p}=0.028)$ and Risk Factors $(\mathrm{F}=2.356 ; \mathrm{p}=0.041)$ subdimension than younger ones (Table 3 ).

They also indicated in the open-ended question the most significant causes of their children's disease to be faith, the will of God, and the evil eye (43.9\%); stress, sorrow, and worry (20.0\%); and nutrition (medicines, genetically modified foods, junk foods, etc.; 12.6\%). Other answers of the parents were infections, germs, viruses, radiation, technology, environmental pollution, genetic factors, and physical weakness or immunodeficiency (Table 4).

\section{Discussion}

In this study, the majority of parents identified specific causal attributions for their children's illness. Overall, the most common causal attribution were risk factors (internal control), indicating most of parents identified causal attributions in their control. However, when they were asked their opinion with open ended, they believe their children's illness occurred out of their control (because of faith, will of God, and evil eyes). We observed variation in causal attributions by parental age and income level.

The literature reports that the most frequently observed causes of childhood cancers are genetic factors, ionizing radiation, and behavioral factors; and that the

Table 2 The Mean Scores of Causal Representations

\begin{tabular}{|c|c|c|c|c|c|c|c|}
\hline Sub-Dimensions & Items & Mean of Item & Min & Max & Mean & SD & Cronbach's Alpha (a) \\
\hline \multirow[t]{5}{*}{ Psychological Attributions } & Stress or worry & 2.02 & & & & & \\
\hline & Family Problems & 1.36 & & & & & \\
\hline & Overwork & 1.72 & 5 & 20 & 1.69 & 3.70 & 0.62 \\
\hline & My emotional state & 1.52 & & & & & \\
\hline & My personality & 1.82 & & & & & \\
\hline \multirow[t]{7}{*}{ Risk Factors } & Genetic factors & 1.98 & & & & & \\
\hline & Diet or eating habits & 2.25 & & & & & \\
\hline & nedical care in her/his past & 1.73 & & & & & \\
\hline & My own behavior & 1.60 & 7 & 28 & 2.94 & 3.60 & 0.66 \\
\hline & Growing & 1.59 & & & & & \\
\hline & alcohol during pregnancy & 1.09 & & & & & \\
\hline & Smoking & 1.51 & & & & & \\
\hline \multirow[t]{3}{*}{ Immunity } & A germ or virus & 2.31 & & & & & \\
\hline & ollution of enviroment & 2.31 & 3 & 14 & 2.39 & 3.02 & 0.48 \\
\hline & Altered immunity & 2.54 & & & & & \\
\hline \multirow[t]{2}{*}{ Accident/ Chance } & Chance or bad luck & 2.14 & 2 & 10 & 1.76 & 1.75 & 0.42 \\
\hline & Accident or injury & 1.37 & & & & & \\
\hline
\end{tabular}


Table 3 Causal representations subscales by sociodemographics

\begin{tabular}{|c|c|c|c|c|}
\hline Socio-demographics & Psychological Attributions & Risk Factors & Immunity & Accident or Chance \\
\hline \multicolumn{5}{|l|}{ Parental Status } \\
\hline Mother & $8.58 \pm 3.75$ & $11.82 \pm 3.58$ & $7.20 \pm 3.07$ & $3.5 \pm 1.78$ \\
\hline Father & $7.00 \pm 2.80$ & $11.29 \pm 3.90$ & $6.88 \pm 2.34$ & $3.70 \pm 1.40$ \\
\hline$p$ value & 0.91 & 0.56 & 0.67 & 0.65 \\
\hline \multicolumn{5}{|l|}{ Parental Age (years) } \\
\hline $19-24(\mathrm{~A})$ & $6.83 \pm 2.65$ & $10.91 \pm 2.90$ & $7.83 \pm 3.78$ & $2.66 \pm 1.23$ \\
\hline $25-30(B)^{*}$ & $7.17 \pm 2.79$ & $10.78 \pm 2.51$ & $7.29 \pm 3.05$ & $3.31 \pm 1.55$ \\
\hline $31-35(C)$ & $8.5 \pm 3.78$ & $12.13 \pm 3.96$ & $7.16 \pm 3.01$ & $3.67 \pm 1.70$ \\
\hline $36-40$ (D) & $8.68 \pm 3.64$ & $11.52 \pm 4.17$ & $7.19 \pm 3.00$ & $3.70 \pm 1.99$ \\
\hline $41-45(E)^{*}$ & $9.77 \pm 3.97$ & $13.3 \pm 3.17$ & $6.88 \pm 2.94$ & $3.77 \pm 1.75$ \\
\hline $46+(F)$ & $8.94 \pm 4.64$ & $11.33 \pm 2.7$ & $7.05 \pm 3.05$ & $2.94 \pm 1.62$ \\
\hline \multirow[t]{2}{*}{$p$ value } & $0.028^{*}$ & $0.041^{*}$ & 0.965 & 0.203 \\
\hline & Between B-E & Between B-E & & \\
\hline \multicolumn{5}{|l|}{ Marital Status } \\
\hline Married & $8.38 \pm 3.62$ & $11.81 \pm 3.62$ & $7.21 \pm 3.04$ & $3.54 \pm 1.76$ \\
\hline Single/Divorced & $8.33 \pm 4.93$ & $8.66 \pm 2.88$ & $5.33 \pm 2.51$ & $3.00 \pm 1.73$ \\
\hline$p$ value & 0.981 & 0.136 & 0.287 & 0.597 \\
\hline \multicolumn{5}{|l|}{ Income Level } \\
\hline Medium $(A)^{*}$ & $7.94 \pm 3.43$ & $11.75 \pm 3.70$ & $7.21 \pm 3.10$ & $3.33 \pm 1.79$ \\
\hline $\operatorname{Low}(B)^{*}$ & $9.40 \pm 4.00$ & $11.91 \pm 3.48$ & $7.10 \pm 2.87$ & $3.87 \pm 1.67$ \\
\hline High $(C)$ & $7.63 \pm 3.44$ & $11.18 \pm 3.51$ & $7.27 \pm 3.43$ & $3.18 \pm 1.53$ \\
\hline \multirow[t]{2}{*}{$\mathrm{p}$ value } & $0.013^{*}$ & 0.810 & 0.964 & 0.066 \\
\hline & Between A-B & & & \\
\hline \multicolumn{5}{|l|}{ Education Status } \\
\hline Illiterate & $8.72 \pm 3.84$ & $12.81 \pm 3.91$ & $6.72 \pm 2.76$ & $4.18 \pm 2.04$ \\
\hline Primary school & $9.08 \pm 3.94$ & $12.21 \pm 3.77$ & $6.90 \pm 3.00$ & $3.78 \pm 1.74$ \\
\hline Secondar school & $7.38 \pm 2.91$ & $11.48 \pm 3.99$ & $7.12 \pm 3.12$ & $3.22 \pm 1.64$ \\
\hline High school & $7.98 \pm 3.22$ & $11.67 \pm 3.43$ & $7.80 \pm 3.02$ & $3.24 \pm 1.84$ \\
\hline Graduate/Postgraduate & $9.09 \pm 6.37$ & $10.3 \pm 2.64$ & $7.35 \pm 2.83$ & $3.36 \pm 1.51$ \\
\hline $\mathrm{p}$ value & 0.131 & 0.379 & 0.169 & 0.359 \\
\hline \multicolumn{5}{|l|}{ Region of Residence } \\
\hline Ankara & $7.97 \pm 3.35$ & $11.8 \pm 3.40$ & $7.60 \pm 3.04$ & $3.57 \pm 1.78$ \\
\hline Outside of Ankara & $8.85 \pm 3.93$ & $11.77 \pm 3.77$ & $6.83 \pm 2.97$ & $3.48 \pm 1.72$ \\
\hline$p$ value & 0.072 & 0.947 & 0.054 & 0.675 \\
\hline \multicolumn{5}{|l|}{ Time of diagnosis } \\
\hline $0-6 \mathrm{mth}$ & $8.28 \pm 3.63$ & $11.75 \pm 3.50$ & $7.21 \pm 2.92$ & $3.22 \pm 1.48$ \\
\hline $7-12 \mathrm{mth}$ & $9.22 \pm 3.98$ & $11.71 \pm 4.17$ & $7.31 \pm 3.10$ & $3.87 \pm 1.75$ \\
\hline $13-60 \mathrm{mth}$ & $8.10 \pm 3.46$ & $11.61 \pm 3.04$ & $7.12 \pm 3.09$ & $3.43 \pm 1.92$ \\
\hline Over $60 \mathrm{mth}$ & $7.00 \pm 3.43$ & $14.1 \pm 3.57$ & $6.50 \pm 2.99$ & $3.4 \pm 1.83$ \\
\hline $\mathrm{p}$ value & 0.195 & 0.297 & 0.936 & 0.209 \\
\hline
\end{tabular}

${ }^{*} \mathrm{p}<0.05$.

factors such as environmental pollution and stress play a less important role.[22,23] The present study indicated that the causes of cancer stated by the parents were different compared to those reported in the medical literature.

In this study, the most common causal attributions were risk factors $(\mathrm{M}=2.94)$. The most common reasons cited within the Risk Factors subdimension were diet or eating habits $(M=2.25)$. According to their open-ended answers, nutrition (medicines, genetically modified foods, junk foods, etc.; $12.6 \%$ ) was the most cited reason. Nutrition/eating habits are well known as individuals have internal behaviors that they can control, and that the lack of adequate consumption of vegetables and fruit increases cancer incidence in the literature.[24] In a study with cancer survivors, eating and diet was also attributed as the most common cause.[11] 
Table 4 Qualitative Answers of Parents about Causal Attribution

\begin{tabular}{lcc} 
Why do you think your child got cancer? & $\mathbf{n}^{*}$ & \%** $^{*}$ \\
\hline Faith, Will of God, Evil eye & 91 & 43.9 \\
Stress, Sorrow, Worry & 41 & 20.0 \\
Nutrition (medicines. genetically & 26 & 12.6 \\
modified foods. etc.) & & \\
Infection, Germs, Viruses & 17 & 8.3 \\
Radiation, Technology, & 12 & 5.8 \\
Environmental pollution & & \\
Genetic factors & 10 & 5.0 \\
Physical weakness/lmmunodeficiency & 9 & 4.4 \\
\hline
\end{tabular}

*Multiple answers were allowed

**The percentages were calculated on the total number of answers.

Similar to this study, previous studies have also indicated this risk factor among the possible causes of cancer.[5,6,25,26,27,28,29,30] However, in Hopman and Rijken's study (2015) [12], it was the third leading cause of the subscales. This situation is thought to arise because of cultural differences.

The second-highest scoring average of the Causal Representation subscale was the Immunity subdimension $(M=2.39)$. In a study of adult cancer survivors in the United States, immunity $(\mathrm{M}=3)$ was the secondmost common subscale [12]. Parents stated their child's altered immunity $(\mathrm{M}=2.54)$ as the most significant cause of cancer within the Immunity subdimension. Many studies reported immunity to be one of the most significant causes of cancer. $[5,25,31,32,26]$ Immunity is especially listed among the risk factors of acute lymphoblastic leukemia (ALL) and non-Hodgkin lymphoma (NHL). $[9,23,33]$ Because the majority of the children in this study were diagnosed with ALL, parents were aware of the risk factors in this type of cancer.

It was also found that environmental pollution $(M=2.31)$ was perceived as among the most significant causes of childhood cancer within the Immunity subdimension. A previous study has also reported that one in four cancer survivors have stated environmental pollution as the cause of the disease.[11] Environmental pollution is external factor and out of an individual's control. However, there is no scientific evidence that environmental pollution is an important cause of cancer.

The Accidental or Chance subscale of the Causal Representation scale had the third highest average score $(M=1.76)$ even though when asked open-ended, it was $43.9 \%$ parents responded fatalistic answers such as the "will of God, faith, evil eye." In both the international and the national literature, patients with
$[6,12,18,25,28,29,34]$ and without $[31,32]$ cancer consider misfortune and bad luck to be among the causes of cancer. Considering that the Turkish society culturally has a fatalistic approach [35], it can be said that misfortune, bad luck, faith, evil eye, etc. are commonly considered as causes of a serious disease such as cancer. The main reason for this may be the cultural structure and the important position of religious beliefs in people's perception of health and disease.[36,37] Abaan (1992) [38] also indicated that the will of God is perceived as a cause of disease.[38] Considering the current study's findings, Turkish people continue to attribute the diseases to external supernatural powers or factors two decades later.

The Psychological Factors subdimensions had the lowest score among the subdimensions $(M=1.69)$. Likewise, the Psychological Factors subdimension $(\mathrm{M}=1.94)$ had the least score in the study on adult cancer survivors in the USA [12]. Within this subdimension, stress $(M=2.02)$ was perceived by the parents as one of the most significant causes of cancer; according to parents' qualitative answers 20\% parents believed stress was their children's illness reason. Although stress is considered a trigger of the carcinogenic process by suppressing the immune system and creating oxidative DNA damage $[39,40]$, a scientific consensus does not exist on the fact that stress is a cause of cancer. Comparing our results to those of other studies, stress has been a common attribution in multiple populations. $[5,18,25,31,32,26,27,29,38]$ The negative effects of stress on health are widely known; therefore, stress is associated with cancer.

\section{Limitations}

The major limitation associated with studies with a cross-sectional design is that direction of causation cannot be established. Although the study sample seems to be limited with only one hospital, it can be generalized to the Turkish population. This is because our hospital caters to patients from all over Turkey because it has one of the largest children's hematology and oncology clinics in the capital city of Turkey.

Because most primary caregivers were mothers, study sample was heterogeneous with regard to parents' sex. This study analyzed only the thoughts of parents of children affected with cancer regarding causes of their children's disease. It was not possible to make causal conclusions regarding the relationship between parents' thoughts on the causes of disease and sociodemographic variables. It is known that time of diagnosis is positively related to families' compliance with the 
disease treatment, coping with the disease, and treatment management. Therefore, determination of the relationship between the variables and the perception of the causes of disease could have strengthened our study findings. Another limitation of the study is that parents and children were not evaluated simultaneously. Addressing the parents' and children's perceptions about the causes of disease together will enable comparisons to be made. This will help determine the effects of parents' perceptions on the causes of disease on coping strategies. Comparisons according to age and diagnostic groups of children were considered to affect the evaluation of parents. For this reason, handling of these variables could have made the study stronger.

\section{Implications for Nursing Practice}

It is important for clinicians planning health education on preventing cancer to devote greater attention to cultural assessment and to include cultural beliefs in cancer care for Turkish pediatric cancer patients and their parents. The cultural beliefs should be included in the planning and evaluation of the case of each affected child. Adopting this approach would provide an opportunity to improve the cultural competency of pediatric nursing. Given the cultural context of illness representations, researchers and health providers must carefully consider how they construct models of parent's ideas about childhood cancer and how they create health interventions. Our results indicate that public health and healthcare efforts should be improved in both general healthcare as well as cancer care.

\section{Conclusion}

Our study results showed that parents of children affected with cancer have similar perceptions regarding cancer to those reported in the literature, but have more fatalistic views because of cultural differences. Education regarding the causes of diseases may help positively change parents' and children's perceptions of the disease. Further studies are needed to analyze the relationship between the perception of both the affected children and their parents on the causes of disease, compliance with treatment, and coping with the disease. The results of this study will guide pediatric nurses within the scope of individualized holistic healthcare. Determining the parents' causal representation of cancer may help healthcare providers plan initiatives to support the development of risk-decreasing health behaviors.

Peer-review: Externally peer-reviewed.
Conflict of Interest: The authors declare that there is no conflict of interest.

Authorship contributions: Concept - F.I.E., S.A.T.; Design - F.I.E., T.A.S., S.A.T.; Supervision - F.I.E.; Materials - F.I.E., T.A.S.; Data collection \&/or processing - T.A.S.; Analysis and/or interpretation - F.I.E., T.A.S.; Literature search F.I.E., T.A.S., S.A.T.; Writing - F.I.E., T.A.S.; Critical review - F.I.E., T.A.S., S.A.T.

\section{References}

1. International Agency for Research on Cancer (IARC). Pres Release 2016. http://www.acco.org/wp-content/ uploads/2016/02/pr241_E.pdf. Accessed Mar 21, 2017.

2. Kutluk MT, Yeşilipek A. Turkish National Pediatric Cancer Registry 2002-2008 (Turkish Pediatric Oncology Group and Turkish Pediatric Hematology Society). J Clin Oncol 2013;31:15.

3. Kästel A, Enskär K, Björk O. Parents' views on information in childhood cancer care. Eur J Oncol Nurs 2011;15(4):290-5.

4. Armay Z, Özkan M, Kocaman N, Özkan S. The Turkish Reliability and Validity Study in Cancer Patients of Illness Perception Questionnaire. Klinik Psikiyatri 2007;10:192-200.

5. Hızel S, Toprak S, Albayrak M, Sanlı C, Koçak Ü. Mothers' knowledge, attitudes, and behaviour concerning childhood cancer in a rural Anatolian province. Gazi Med J 2009;20(1):3-6.

6. Hoogerwerf MA, Ninaber MK, Willems LN, Kaptein AA. "Feelings are facts": illness perceptions in patients with lung cancer. Respir Med 2012;106(8):1170-6.

7. Watanabe A, Nunes $T$, de Abreu G. Japanese parents' perception of disclosing the diagnosis of cancer to their children. Clin Child Psychol Psychiatry 2014;19(1):125-38.

8. Salvador Á, Crespo C, Martins AR, Santos S, Canavarro MC. Perceptions About Their Child's Illness in Pediatric Cancer: Links with Caregiving Burden and Quality of Life. J Child Fam Stud 2015;24:1129-40.

9. Belson M, Kingsley B, Holmes A. Risk factors for acute leukemia in children: a review. Environ Health Perspect 2007;115(1):138-45.

10. Weinman J, Petrie KJ, Moss-Morris R, Horne R. The illness perception questionnaire: A new method for assessing the cognitive representation of illness. Psychol Health 1996;11:431-45.

11. Ferrucci LM, Cartmel B, Turkman YE, Murphy ME, Smith T, Stein KD, et al. Causal attribution among cancer survivors of the 10 most common cancers. J Psychosoc Oncol 2011;29(2):121-40.

12. Hopman P, Rijken M. Illness perceptions of cancer patients: relationships with illness characteristics and cop- 
ing. Psychooncology 2015;24(1):11-8.

13. Ljungman G, McGrath PJ, Cooper E, Widger K, Ceccolini J, Fernandez CV, et al. Psychosocial needs of families with a child with cancer. J Pediatr Hematol Oncol 2003;25(3):223-31.

14. Pöder U, Ljungman G, von Essen L. Parents' perceptions of their children's cancer-related symptoms during treatment: a prospective, longitudinal study. J Pain Symptom Manage 2010;40(5):661-70.

15. Kim SH. Mothers' Experiences of Maternal Role Performance for Their Children with Cancer in Korea. Adv Sci Technol Lett (Healthcare and Nursing) 2015;88:109-12.

16. Lowery BJ, Jacobsen BS, DuCette J. Causal attribution, control, and adjustment to breast cancer. J Psychosoc Oncol 1993;10(4):37-53.

17. Berckman KL, Austin JK. Causal attribution, perceived control, and adjustment in patients with lung cancer. Oncol Nurs Forum 1993;20(1):23-30.

18. Wold KS, Byers T, Crane LA, Ahnen D. What do cancer survivors believe causes cancer? (United States). Cancer Causes Control 2005;16(2):115-23.

19. Ashley L, Smith AB, Keding A, Jones H, Velikova G, Wright P. Psychometric evaluation of the revised Illness Perception Questionnaire (IPQ-R) in cancer patients: confirmatory factor analysis and Rasch analysis. J Psychosom Res 2013;75(6):556-62.

20. The Ministry of Health. Cancer Statistics of Turkey 2013. Available at: http://kanser.gov.tr/Dosya/ca_istatistik/ANA_rapor_2013v01_2.pdf. Accessed Jun 12, 2017.

21. Moss-Morris R, Weinman J, Petrie K, Horne R, Cameron L, Buick D. The Revised Illness Perception Questionnaire (IPQ-R). Psychol Health 2002;17:1-16.

22. Colditz GA, Samplin-Salgado M, Ryan CT, Dart H, Fisher L, Tokuda A, et al; Harvard Center for Cancer Prevention. Harvard report on cancer prevention, volume 5: fulfilling the potential for cancer prevention: policy approaches. Cancer Causes Control 2002;13(3):199212.

23. American Cancer Society. Cancer in children and adolescents. Cancer facts and figures. 2014. Available at: http://www.cancer.org/acs/groups/content/@research/ documents/webcontent/acspc-041787.pdf. Accessed Jun 4, 2017.

24. Ames BN, Gold LS, Willett WC. The causes and prevention of cancer. Proc Natl Acad Sci U S A 1995;92(12):5258-65.

25. Liman T. The relationship between the illness perception of the adolescents with chronic illness and the level of anxiety and depression. Unpublished Doctoral Dissertation, DEU Institute of Health Sciences. 2011. Availablet at: http://acikerisim.deu. edu.tr/xmlui/bitstream/handle/12345/9948/301232. pdf? sequence $=1$ \&isAllowed=y. Accessed Jul 3, 2018.

26. Kwate NO, Thompson HS, Valdimarsdottir HB, Bovb- jerg DH. Brief report: etiological attributions for breast cancer among healthy African American and European American women. Psychooncology 2005;14(5):421-5.

27. Giannousi Z, Manaras I, Georgoulias V, Samonis G. Illness perceptions in Greek patients with cancer: a validation of the Revised-Illness Perception Questionnaire. Psychooncology 2010;19(1):85-92.

28. Llewellyn CD, Miners AH, Lee CA, Harrington C, Weinman J. The illness perceptions and treatment beliefs of individuals with severe haemophilia and their role in adherence to home treatment. Psychol Health 2003; 18:185-200.

29. Price A, Goodwin L, Rayner L, Shaw E, Hansford P, Sykes N, et al. Illness perceptions, adjustment to illness, and depression in a palliative care population. J Pain Symptom Manage 2012;43(5):819-32.

30. Yllmaz-Karabulutlu E, Karaman S. Evaluation of cancer patients perception of illness. Journal of Health Science and Profession 2015;2:271-84.

31. Yorulmaz H, Keçeci N, Tatar A. The effect of illness perception on quality of life in patients with chronic kidney failure. Literary Symposium 2014;1:40-5.

32. Kocaman-Yıldırım N, Okanlı A, Yılmaz Karabulutlu E, Karahisar F, Özkan S. Effects of illness perception on anxiety and depressive symptoms in hemodialysis patients: A multi-center study. Anadolu Psikiyatri Derg 2013;14:252-9.

33. Kinlen L. Childhood leukaemia, nuclear sites, and population mixing. Br J Cancer 2011;104(1):12-8.

34. Law GU, Kelly TP, Huey D, Summerbell C. Self-management and well-being in adolescents with diabetes mellitus: do illness representations play a regulatory role? J Adolesc Health 2002;31(4):381-5.

35. Esmer Y. Turkey Values Survey 2016. Availble at: http:// content.bahcesehir.edu.tr/public/files/files/ATLAS\%20 SUNUM\%202_10_2012\%20(2).pdf. Accessed Jun 5, 2017.

36. Landrine $\mathrm{H}$, Klonoff EA. Cultural diversity in causal attributions for illness: the role of the supernatural. J Behav Med 1994;17(2):181-93.

37. Dein S. Explanatory models of and attitudes towards cancer in different cultures. Lancet Oncol 2004;5(2):119-24.

38. Abaan SE. The perceptions of cancer patients of their illness. [Unpublished Doctoral Dissertation. Ankara: Hacettepe University Institute of Health Sciences; 1992.

39. Godbout JP, Glaser R. Stress-induced immune dysregulation: implications for wound healing, infectious disease and cancer. J Neuroimmune Pharmacol 2006;1(4):421-7.

40. Valko M, Rhodes CJ, Moncol J, Izakovic M, Mazur M. Free radicals, metals and antioxidants in oxidative stressinduced cancer. Chem Biol Interact 2006;160(1):1-40. 